\title{
Laparoscopic vs Open Appendectomy : A Comparative Study
}

\author{
Sardar Rezaul Islam* \\ Kamal Pasha \\ Shahinur Rahman \\ Emdad Nasir \\ Emon Hanif \\ Auditi Barman
}

Department of Surgery

Jahurul Islam Medical College \& Hospital

Kishoregoni, Bangladesh.
Correspondence to:

\section{Dr. Sardar Rezaul Islam}

Associate Professor

Department of Surgery

Jahurul Islam Medical College \&hospital

Kishoregoni, Bangladesh.

Mobile: +880-1746603305

E-mail: islamreza@hotmail.com

\begin{abstract}
Backgraound: Open appendectomy (OA) has been the treatment of choice for acute appendicitis since its introduction by Mc-burney in 1884. Laparoscopic appendectomy(LA) though widely practiced, has not gained universal approval. LA was first described in 1983. Some early studies showed equivocal results about benefit of LA. Recent studies showed overall benefit in favour of LA. So far no such a large study was done in any Bangladeshi hospital. So, we decided to do this study with a view to evaluate the therapeutic benefit of LA by comparing with conventional OA . Materials and methods: We collected data of 763 appendectomies done in Jahurul Islam medical college hospital from July 2007 to June 2012 for a period of 5 years. Out of them 448 had conventional OA and 315 had LA. We compared the mean operation time, time of first oral feeding, narcotic analgesic requirement, duration of post operative hospital stay. Results: We found that mean operation time was $33 \pm 5.8$ minute and $37 \pm 7.5$ minute in LA and OA respectively. Duration of post operative hospital stay was 1.2 days shorter in Laparoscopic group. LA required 1.1 shots of less analgesic than OA. Oral feeding was resumed 21 hours earlier following LA compared to OA. Laparoscpic appendectomy was safely performed in paediatric patient without any adverse effect. We also found that, in female patient, concurrent ovarian cysts, tubal pregnancy and endometriosis can be diagnosed and managed laparoscopically in the same sitting. Conclusion: Our study found that laparoscopic appendectomy is an effective and safe procedure irrespective of age and sex of the patient. LA has added advantage of early return of bowel movement, less post-op hospital stay and less requirement of narcotic analgesic.
\end{abstract}

Key words: Acute appendicitis; laparoscopic appendectomy; open appendectomy; laparoscopic vs open appendectomy.

\section{INTRODUCTION}

Open appendectomy has been a safe and effective operation for acute appendicitis for more than a century. According to the literature, approximately $7 \%$ of the population develope appendicitis in their life time, with peak incidence between the ages of 10 and 30 years, thus making appendectomy the most frequently performed abdominal operation ${ }^{1}$. Recently, several authors proposed that the new technique of laparoscopic appendectomy should be the preferred treatment for acute appendicitis. However,unlike laparoscopic cholecystectomy, laparoscopic appendectomy(LA) has not yet gained popularity ${ }^{2}$. Laparoscopic cholecystectomy is now considered a standard method of performing cholecystectomy and has mostly replaced the old method throughout the world, while appendectomy has yet to achieve such popularity ${ }^{3}$. Since its introduction by Mcburney in 1884, appendectomy has been a treatment of choice for acute appendicitis ${ }^{4}$. For more than a century, open appendectomy remained the gold standard of treatment of acute appendicitis and for interval appendectomy. 
In 1981, Semm, a German gynecologist performed the first laparoscopic appendectomy ${ }^{5-6}$. Despite its use even before laparoscopic cholecystectomy, LA has not yet emerged as gold standard appendectomy. LA has potential advantages of shorter hospital stay, early mobilization, early return of bowel function, acceptable complication rate along with the recent enthusiasm of minimally invasive surgery. These definite advantages have led some authors to advocate this approach as the procedure of choice for uncomplicated appendicitis $^{7-8}$.

\section{PATIENTS AND METHODS}

We conducted retrospective review of consecutive patients with appendectomy in Jahurul Islam Medical College Hospital between July 2007 and June 2012. Jahurul Islam Medical College is community based teaching hospital, which mostly caters rural population of the surrounding districts. All the operations were performed in the two surgical units of the hospital.

Pre operative diagnosis was made using history, clinical examination coupled with laboratory findings and imaging studies. In open group, only appendix removed via McBurney's incision was included in the study. Patients in whom midline incisions were given were excluded from the study. Operating time was calculated from the time of first incision up to the placement of last stitch on the closing wound. Post operative hospital stay, in days, was defined as the time the patient left the operation theater up to the time of discharge from the hospital. Number of shots of injectable narcotic analgesics given to the patients postoperatively was recorded. Time of resumption of oral food, in hours, was calculated from the time of surgery.

Data were analyzed using standard statistical method. Descriptive statistical including means, medians, standard deviation, percentages were used to describe study population on all variables. For categorical variables $\mathrm{x}^{2}$ test and Fisher exact test were used to make comparison.

\section{Procedure Description}

For the laparoscopic approach, a 10-mm trocar was placed at the umbilicus and 2 additional $5 \mathrm{~mm}$ and a $10 \mathrm{~mm}$ trocars were inserted in the lower abdomen and right hypochondrium respectively (Fig-1). The meso-appendix was transected after applying titanium hemoclip. The bases of the appendix were ligated with an endoloop constructed with a Roeder's knot on a No-1 vicryl thread (Fig-2). Usually a single endoloop was used. The specimens were removed via the umbilical port. In case of peritoneal collection only suction was used. No irrigation was used.

In open approach, we used traditional Grid -Iron incision over the Mc-Burney's point. The appendix bases were transfixed with a no1/0 vicryl suture. Appendix base was not invaginated.

All patients received preoperative and post operative antibiotic. A combination of $2^{\text {nd }}$ or $3^{\text {rd }}$ generation cephalosporin and metronidazole were used. In presence of severe systemic sign an aminoglycoside, usually Amikacin was added. All patients were discharged on resumption of solid food and complete remission of fever.

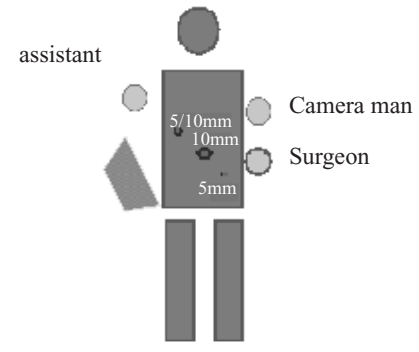

Figure 1: Ergonomics

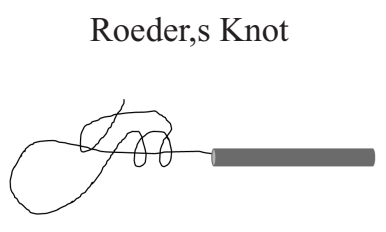

Figure 2: Roeder's knot

\section{RESULTS}

During study period, total 763 appendectomy were performed, of which 448 were open and 315 were laparoscopic. Ages of the patients ranged from 2 to 72 years. In the laparoscopic group $123(39 \%)$ were adult male, $176(56 \%)$ were adult female, $16(5 \%)$ were children. Operating time in LA was $33 \pm 5.8$ minutes and in OA was $37 \pm 7.5$ minute (OR-0.79, CI-95\%). Conversion rate for LA was $3.4 \%$ (11 cases). Average number of shots of narcotic analgesics required for OA was 3.1 while for LA was 2 (OR-0.30, CI 95\%). Oral feeding was resumed after average 59 hours after surgery in OA and average 38 hours after LA (OR-0.41, CI 95\%). Mean difference were 21 hours in favor of LA. The post operative hospital stay was 4.4 days in OA and 3.2 in LA (OR-0.47, CI95\%). LA group required 1.2 days less post op hospital stay than OA (Table 1). Some concomitant pathology was managed during LA including 10 cholecystectomies, 4 tubal pregnancy and 6 ovarian cystectomies (Table 2). There was no death in either group.

Table 1: Outcome comparison between LA and OA

\begin{tabular}{|c|c|c|c|c|}
\hline Outcome & LA & $\begin{array}{c}\mathrm{OA} \\
\text { difference }\end{array}$ & Mean & Odds ratio \\
\hline $\begin{array}{l}\text { Operating time } \\
\text { (minute) }\end{array}$ & $33 \pm 6$ & $37 \pm 7.5$ & -4 & $\begin{array}{c}0.79 \\
\text { CI } 95 \%\end{array}$ \\
\hline $\begin{array}{l}\text { Number of analgesic } \\
\text { doses (narcotic) }\end{array}$ & 2 & 3.1 & -1.1 & $\begin{array}{c}0.30 \\
\text { CI } 95 \%\end{array}$ \\
\hline $\begin{array}{l}\text { Resumption } \\
\text { of oral food (Hours) }\end{array}$ & 38 & 59 & -21 & $\begin{array}{c}0 ; 41 \\
\text { CI } 95 \%\end{array}$ \\
\hline Hospital stay (days) & 3.2 & 4.4 & -1.2 & $\begin{array}{c}0.47 \\
\text { CI } 95 \%\end{array}$ \\
\hline
\end{tabular}

Table 2: Con-commitment pathology managed during LA Con-commitent pathology Number

Lap Cholecystectomy 10

Excision of tubal pregnancy

4

Lap Ovarian cystectomy 


\section{DISCUSSION}

Sixteen $(5 \%)$ of our patients were children. We used the same trocar positions in children as in adults. We inserted camera trocar slightly above the umbilicus in very small children. The $\mathrm{CO}_{2}$ pressure was kept at 11 or $12 \mathrm{~mm}$ of $\mathrm{Hg}$ in children. We did not encounter any difficulty while operating on children, except crowding of instruments. There are many studies done on lap appendectomy on children. No difference in mortality or major complication rate was observed between LA and OA among children?

Nine of our patients were above 60 years. No special problem was encountered during operating in these patients. But we did not attempt LA on patients with COPD and heart failure, as increased intra-abdominal pressure may compromise cardiovascular hemodynamics ${ }^{10}$.

We rarely found very obese patient in this rural based medical college hospital. OA in obese patient is particularly difficult through McBurney's incision and often requires larger incision. LA in obese patient has extra advantage in this regard ${ }^{11}$.

As concomitant pelvic pathology can be diagnosed and managed very effectively during laparoscopy, we have managed cases of ruptured ectopic pregnancy and ovarian cysts during this period in women of reproductive age group. Any patient of reproductive age having suspected appendicitis should have laparoscopic appendectomy as any concomitant pelvic pathology can be dealt with in the same laparoscopic session. We also removed gall bladders for USG proved gall stones during laparoscopic appendectomies. In these cases we used conventional 4 ports as in laparoscopic cholecystectomies and did not insert any extra port for removal of appendices.

Complications following LA are less than in OA. Although some studies show higher intra-abdominal abscess formation in LA, others report no significant difference between $\mathrm{LA}$ and $\mathrm{OA}^{12-16}$.

During the early period of our study we were inserting double ligature at the base of the appendix to secure the stump. Later on we started practicing single loop to secure appendix base as there was no difference in post operative mortality and morbidity between the use of single loop and double loop in $\mathrm{LA}^{17}$. As a result operation time was reduced by few minutes.

When we came across to perforated appendix and pus collection, we used suction only to clean the pus from the peritoneal cavity. We did not use irrigation at all.
A prospective randomized trial was published in the literature, which concluded that there is no significant difference in outcome between suction and irrigation combined and suction alone during LA in case of perforated appendicitis ${ }^{18}$. In this study the incidence of residual abscess was found to be same in both group with perforated appendicitis. Duration of hospital stay was also not different.

Here we like to mention that we tend to discharge patient slightly later in this rural based medical college hospital. Our patients come from distant places. As a result they cannot come to the hospital at odd hours of the day in case any post-op emergency arises at home.

Adhesion formation is now one of the common complications following intra abdominal operation. A study has shown that rate of adhesion is about $80 \%$ in OA compared to $10 \%$ in LA three months after the surgery ${ }^{19}$.

Regarding the indication of LA we may include females of reproductive age group, doubtful diagnosis of appendicitis, recurrent appendicitis, high working class, obese patient, cirrhosis of liver, sickle cell disease and immuno-compromised patient.

General anaesthesia and pneumoperitoneum required for laparoscopic procedure poses risks to certain group of patients with cardio-respiratory compromise. So LA is not recommended for patients with COPD or cardiac disease. LA should also be avoided in previous lower abdominal surgery, generalized peritonitis and stump appendicitis.

Laparoscopic appendicectomy in pregnancy is associated with a low rate of intra-operative complications in all trimesters. However, LA in pregnancy is associated with a significantly higher rate of fetal loss compared to open appendicectomy. Open appendicectomy would appear to be the safer option for pregnant women for whom surgical intervention is indicated ${ }^{20}$.

\section{CONCLUSION}

Laparoscopic appendectomy is an effective and safe option and the procedure of choice for most patients regardless of age, sex and BMI. It requires less operative time, has minimal complications and less hospital stays and has the advantage of managing concomitant pathologies.

\section{DISCLOSURE}

All the authors declared no competing interest. 


\section{References}

1. Kumar B, Samad A, Khanzada TW, Laghari MH, Shaikh AR. Superiority of Laparoscopic appendectomy over open appendectomy: The Hyderabad experience. Rawal Med J 2008; 33:165-8.

2. Peiser JG, Greenberg D. Laparoscopic versus open appendectomy: results of a retrospective comparison in an Israeli hospital. Isr Med Assoc J 2002; 4: 91-4.

3. Kehagias I, Karamanakos SN, Panagiotopoulos S, Panagopoulos K, Kalfarentzos F. Laparoscopic versus open appendectomy: which way to go? World J Gastroenterol 2008; 14: 4909-1.

4. McBurney C. IV. The Incision Made in the Abdominal Wall in Cases of Appendictis, with a Description of a New Method of Operating. Ann Surg 1994; 20: 38-43.

5. Chung RS, Rowland DY, Li P, Diaz J. A meta-analysis of randomized controlled trials of laparoscopic versus conventional appendectomy. Am J Surg 1999; 177: 250-6.

6. Semm K. Endoscopic appendectomy. Endoscopy 1983; $15 ; 59-64$.

7. Gross E, et al. Laproscopic versus conventional appendectomy - a comparison with reference to early postoperative complication. Zentralbl Chir 1998; 123: $858-62$.

8. Tranoff M, Atabek U, Goodman M, Alexander JB, Chrzanowski F, Mortman K, et al. A comparison of laparoscopic and open appendectomy. J Soc Laparoendosc Surg 1998; 2: 153-8.

9. Paya K, Fakhari M. Journal of Soc Laparoendosc surg. 2000;4: 121-124.

10. Markar SR, Black S, Zaidi A. Laparoscopic vs open appendectomy in older patient. JAMA Arch Surgery, 2012;147(6): 557-562.
11. Mason RJ, Moazzez A, Moroney JR, Katkhouda N. Laparoscopic vs Open Appendectomy in Obese Patients: Outcomes Using the American College of Surgeons National Surgical Quality Improvement Program Database . Journal of the American College of Surgeons 2012; 215 (1): 88-89.

12. Laparoscopic surgery, -Mac Graw Hill; 2003; 230295.

13. Hall K, Banon MP, Harmesen W, Sarr MG. A prospective randomized comparison of laparoscopic appendectomy with open appendectomy: Clinical and economic analyses. Surgery, 2001; 129( 4):13901400.

14. Ingram AP, Cohen ME, Pritts TA, Esposito TJ, Comparison of outcomes after laparoscopic versus open appendectomy for acute appendicitis at 222 ACS NSQIP hospitals. Surgery 2010; 148 (4): 625-37.

15. Paterson HM, Qadan M, de Luca SM, Nixon SJ, Brown SP. Changing Trends in Surgery for acute appendicitis, British J Surg 2008; 1 95(3): 59-68.

16. Paik PS et al, intraabdominal abscess following laparoscopic appendicitis.J Gastroentest Surg 1997; 1(2): 188-193.

17. Beldi G, Muggli K, Laparoscopic appendectomy using endo-loops-A prospective randomized controlled trial, Surgical endoscopy 2004;18:749-50.

18. St Peter SD, Adibe OO, Iqbal CW, Fike FB, Sharp SW, et al. Irrigation Versus Suction Alone During Laparoscopic Appendectomy for Perforated Appendicitis. Annals of Surgery 2012; 256(4): 581-585.

19. Cushiery A, Appendectomy- Laproscopic or open? Surg Endosc 1997; 11:319-320.

20. Walsh C, Tang T, Walsh SR, Int J Surg. 2008; 6(4): $339-44$. 